\title{
Vortices in dam reservoir: A case study of Karun III dam
}

\author{
MARYAM AZARPIRA ${ }^{1}$, HAMED SARKARDEH ${ }^{2, *}$, \\ SASAN TAVAKKOL ${ }^{3}$, REZA ROSHAN ${ }^{4}$ and HOSSEIN BAKHSHI ${ }^{2}$ \\ ${ }^{1}$ Department of Civil and Environmental Engineering, Amirkabir University \\ of Technology, Tehran P.O. Box: 15914, Iran \\ ${ }^{2}$ Department of Engineering, Hakim Sabzevari University, Sabzevar P.O. Box: \\ 9617976487, Iran \\ ${ }^{3}$ Department of Civil and Environmental Engineering, University of Southern \\ California, Los Angeles, CA P.O. Box: 90089, USA \\ ${ }^{4}$ Water Research Institute (WRI), Hakymia, Tehran P.O. Box: 313/16765, Iran \\ e-mail: azarpira@aut.ac.ir; sarkardeh@hsu.ac.ir; tavakkol@usc.edu; \\ r.roshan@wri.ac.ir; h.bakhshi@hsu.ac.ir
}

MS received 27 June 2013; revised 16 February 2014; accepted 20 February 2014

\begin{abstract}
The present study focuses on the effect of vortex formation on plane velocities in a reservoir. Velocity measurements are performed in the hydraulic model of Karun III dam and hydropower plant. Different vortices were produced at the horizontal intake by changing the submerged depth. Tangential velocities were measured on a rectangular mesh in the reservoir. The results were then processed to plot the contour lines of the plane velocities and study the effect of vortex formation on the flow condition in the reservoir. Contour lines in different submerged depths show that circulation zones are formed in different potential locations over the intakes causing vortex formation. These results were correlated with the location of the appearing vortices observed in the experiments. Experimental data of this study could be useful for numerical modelling of vortex in the reservoirs.
\end{abstract}

Keywords. Tangential velocity; reservoir; vortex; velocity measurement; Karun III dam and hydropower plant.

\section{Introduction}

Formation of vortices at power intakes is a challenging problem for hydraulic engineers. The formation of vortex at the entrance of power intakes of hydropower plants in the reservoir of dams may have destructive consequences. Typical problems may occur when free surface vortex is present in the reservoir which includes decreasing the efficiency of turbines and their vibration, increasing hydraulic losses at the entrance of power intakes, entraining debris which may cause blockage of trash racks, entraining air into the power tunnel, and reducing longevity of turbines

*For correspondence 
(Knauss 1987). Vertical anti-vortex walls and anti-vortex plates are usually considered to be among the effective means for eliminating a vortex.

The possibility of vortex formation can be observed by its velocity in the reservoir, $v_{\theta}$, which is defined as the tangential velocity on an arbitrary point in the reservoir. As the tangential velocity of vortices increases, stronger swirl flow and more air entrainment is expected in the power tunnels. It is therefore important to determine reasons of creation of circulation in studies of vortex formation. In order to study vortex formation, one may investigate the velocity pattern in the reservoir of dam by measurements to ensure that velocities show circulation when a vortex is formed at the intake. Rankine (1858) suggested a simple model for modelling intake vortex. In this model, the inner core is assumed as a forced and the outer region as a free vortex. Based on this model, the boundary between the forced inner and irrotational outer free vortex is located at a distance equal to the radius of the intake from the axis of rotation.

Vortices may be formed with different strengths and properties. In the most recent classification by Sarkardeh et al (2010), vortices regarding their properties are divided into three general classes. Vortices of Class $\mathrm{C}$ are considered as the safe vortices. A weak rotation of flow or a small drop may be observed in the water surface in Class $\mathrm{C}$. In vortices of Class $\mathrm{B}$, the rotation of flow is extended down to the intake entrance and it may drag debris or trash into the intake. Vortices of Class A are assumed as dangerous vortices and should be avoided. In this class, air bubbles are entrained from water surface and are transported down to the tunnel and in the strongest state, a stable air core is formed in the center of the vortex steadily conveying are into the power tunnel (figure 1).

A key parameter in vortex studies is the intake submerged depth, $S$, which is the distance between water surface and intake axis (figure 2). To prevent formation of an air core vortex, a minimum operating depth, called critical submerged depth, denoted by $S_{c r}$, is recommended for the intakes.

Strength of surface vortices is significantly influenced by the reservoir geometry (Sarkardeh et al 2012). The correct identification of the flow pattern, and a quantification of the velocities characterizing the reservoir condition, eddies and recirculation zones, is important for engineering applications as well as design of an anti-vortex structure. As velocity governs the mechanisms of turbulence, its accurate assessment would allow predicting the potential vortex zones. This information is necessary for an efficient dam design.

Many studies are carried out on vortices at the reservoirs. De Siervi et al (1982) studied different vortex mechanisms. Constantinescu \& Patel (1998, 2000) and Montazerin et al (2001) conducted numerical investigations on vortices at the reservoir. Carriveau et al (2009) performed an experimental investigation on vortices at deep hydraulic intakes. Camnasio et al (2011) experimentally studied the velocity fields in rectangular shallow reservoirs. Sarkardeh et al (2013) also studied the velocity field in a reservoir in the presence of surface vortices experimentally. They observed a downward conical flow over the intake axis and an upward one below the intake axis in the reservoir. Most published researches focus on predicting critical submerged

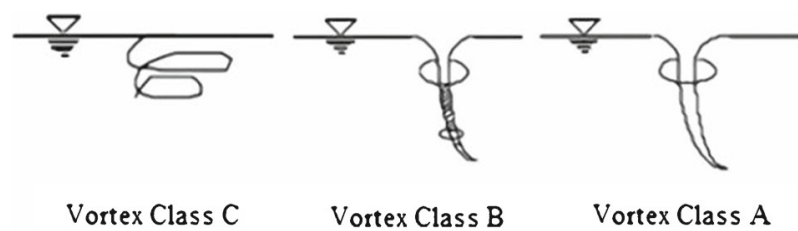

Figure 1. Vortex classification. 


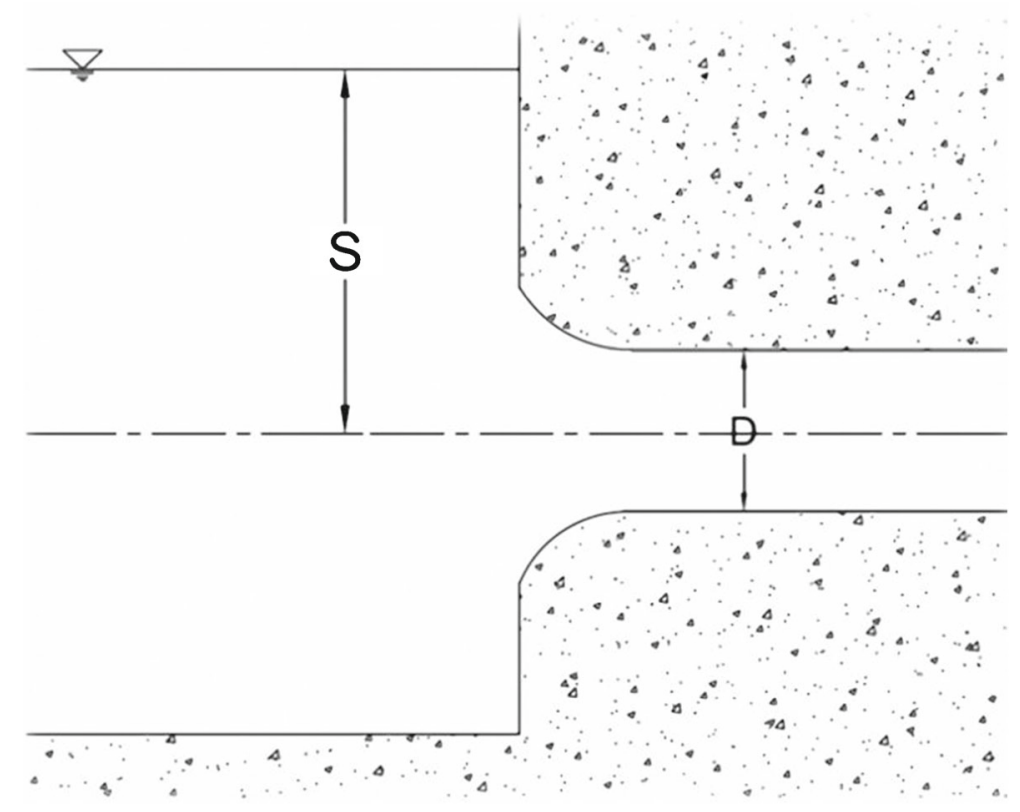

Figure 2. Submerged depth at intakes (Sarkardeh 2009).

depth (Denny \& Young 1957; Berge 1966; Gordon 1970; Reddy \& Pickford 1972; Daggett \& Keulegan 1974; Amphlett 1976; Chang 1977; Anwar et al 1978; Jain et al 1978; Anwar \& Amphlett 1980; Odgaard 1986; Hite \& Mih 1994; Sarkardeh et al 2010; Travis \& Mays 2011; Yildirim et al 2012), by neglecting the effect of the flow fields and the flow pattern on free surface vortex formation, which strongly influences the analysis of critical submerged depth in the reservoir. Existing literatures on vortex prevention also mainly focus on structural methods at intake entrance (Anwar et al 1978; Denny \& Young 1957; Knauss 1987; Johnson 1972; Chen et al 2004; Amiri et al 2011; Taghvaei et al 2012).

This study presents experimental results carried out on hydraulic model of Karun III Dam and Hydropower Plant with large enough scale of reservoir and intake. While previous experimental researches focused on vortex at the intake entrance, the present study aims to measure velocities in the reservoir in each test. Therefore, plane velocity components are measured, allowing a description of the flow in the reservoir. Three intake submerged depths are selected and in each test velocities are measured in two water elevations.

\section{Experimental set-up}

To supply water demand for irrigation and drinking purposes and also power generation, Karun III dam and hydropower plant was constructed on the Karun River in the province of Khuzestan, Iran. The power plant consists of 8 units each $250 \mathrm{MW}$. The dam is a double arch concrete type, $205 \mathrm{~m}$ height from the foundation and $185 \mathrm{~m}$ height from the river bed. Two power tunnels with $12.6 \mathrm{~m}$ diameter were constructed to supply the 8 units.

Design discharge of intake is $750 \mathrm{~m}^{3} / \mathrm{s}$. Dimensions of the intakes are $24.6 \times 24.6 \mathrm{~m}$. Elevation of intake bottom is 765.5 meters above the sea level (MASL) and intake axis is located at 780 MASL. Maximum and minimum reservoir operation levels are 840 and 800 MASL, respectively. 
In physical modelling, the largest scale which satisfies the minimum criteria to minimize the scale effects is acceptable. In the present physical model of vortex, the base of similitude was Froude number (Anwar et al 1978; Hite \& Mih 1994) and to avoid scale effects and eliminate effects of viscosity and surface tension, various suggested criteria (Daggett \& Keulegan 1974; Anwar et al 1978; Padmanabhan \& Hecker 1984; Odgaard 1986; Jain et al 1978) were checked. The hydraulic model of the dam was a 1:33.33 scale model constructed in Hydraulic Laboratory of Water Research Institute in Tehran. Figure 3 shows the hydraulic model of Karun III Dam and Hydropower Plant reservoir intake entrance and part of the downstream tunnels.

In the present hydraulic model study, principles of similitude to correlate model and prototype behaviour were carefully applied to the desired physical behaviour of the model to simulate that of the prototype. Dimensional analysis was performed based on relationship of the physical quantities involved in the dynamic behaviours of a vortex flow in a hydraulic structure. Three basic types of similitude, geometric, kinematic and dynamic similarity were checked between model and prototype. To avoid the effect of reservoir walls on inlet flow pattern, a length of $226 \mathrm{~m}$ and width of $240 \mathrm{~m}$ of the reservoir in the prototype is constructed with masonry materials. Moreover, in the hydraulic model, one side of the reservoir is made from Perspex to see flow pattern in front of the intake. Four sharp crested rectangular spillways installed on the downstream of model are used for each unit for discharge measurement. The velocities are measured by using a propeller velocity meter. Also, a limnimeter with $0.1 \mathrm{~mm}$ accuracy is used to measure elevation of the water surface. The velocities were measured using a propeller velocity meter with accuracy of $1 \%$ measured velocity. A virtual mesh was generated over the reservoir model and in junction of the mesh, the velocities were measured. In all experiments both intakes were fully opened. Formation of weak vortices is difficult to distinguish. Therefore, some little and buoyant particles were released in the flow to see the Class of formed vortices as shown in figure 4. It should be noted that in the present work to ensure that the results are reliable and repeatable some works were performed before and after each test. The model set-up was run for about two hours before beginning each test to ensure that the system has reached its steady state. A sensitivity analysis was performed on during time of velocity measurement in each point in

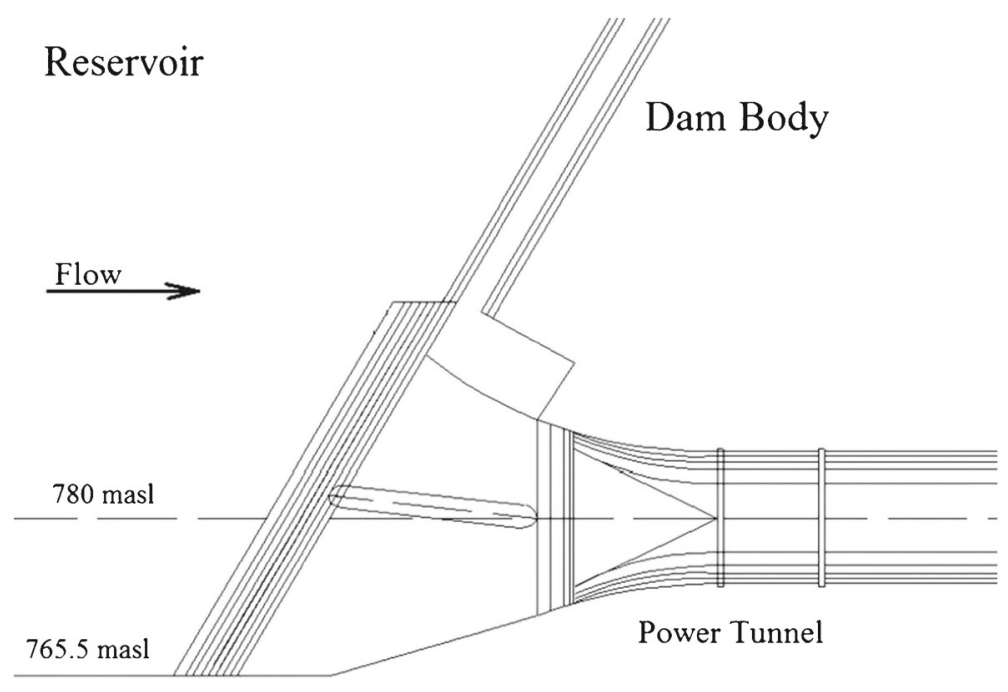

Figure 3. Side view of Karun III power intakes. 


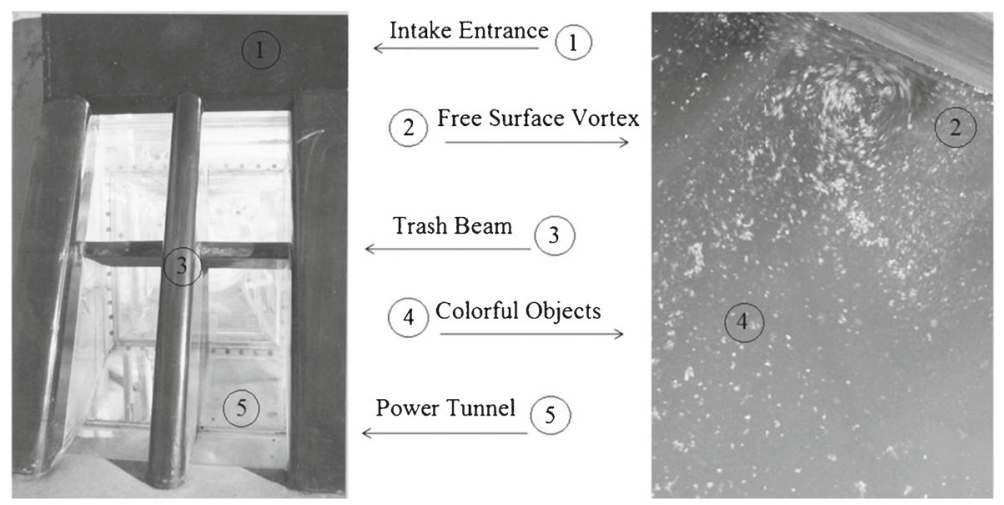

Figure 4. Constructed model of power intake and formation of free surface vortex.

the reservoir. Moreover, in some random points, the velocity was measured and compared with the same point in the previous experiment. A final visual check was also employed on the plotted data to recognize the probable noisy data.

\section{Results and discussions}

In the first part of the experiments, the critical submerged depth was estimated by experimental works and empirical equations. Model studies showed that $S / D=1.6$ produces Class A vortices. As mentioned, many researchers have tried to find a relation for $S_{c r}$ based on prototype and physical model studies. Some of these relationships correlate $S_{c r} / D$ to flow velocity in the tunnel, $v$, where $D$ is the tunnel diameter such as Denny \& Young (1957): $S_{c r} / D=0.151+0.305 v-0.01 v^{2}$; Nagarkar et al (1987): $S_{c r} / D=4.4 \times v^{0.54} \times D^{-0.73}$ and some have correlated it to the intake Froude number defined as $F r=v / \sqrt{ } g D$ where $g$ is the gravitational acceleration such as Gordon (1970): $S_{c r} / D=2.3 F r$; Reddy \& Pickford (1972): $S_{c r} / D=1+F r$; Sarkardeh et al (2010): $S_{c r} / D=2(1 / Z)^{0.008} \times F r^{0.334}$ where $Z$ is the intake head wall slope. For estimating critical submerged depth at horizontal intakes, the mentioned empirical equations are compared with the experimental data in figure 5.

As can be seen in figure 5, Denny \& Young (1957) and Sarkardeh et al (2010) predicted critical submerged depth closer to the result of experiment. However, Gordon (1970) and Reddy \& Pickford (1972) underestimated and Nagarkar et al (1987) overestimated $S_{c r}$.

In the second part of the experiments, plane velocities were measured on a rectangular grid in two levels of the reservoir (near the water surface level and in the intake axis level). Figure 6 presents plane velocity contour lines in the reservoir for $S / D$ equal to 1.6.

As can be seen in figure 6, plane velocity contour lines at the water surface show a downward conical flow down to the intake. At the intake axis, a main flow could be identified towards the intake. It is stronger at the intake entrances. At this reservoir elevation, strongest vortices (Class A) were observed. Increasing the reservoir elevation caused a decrease in the formed vortices class. Figure 7 shows the decrease in plane velocities in the reservoir.

At $S / D=3.2$, weak vortices (Class $\mathrm{C}$ ) were observed in the model. The plane velocities, as can be seen in figure 8 , are reduced significantly. It could be concluded that velocities in the reservoir are influenced strongly by the class of the formed vortices. Increasing the submerged depth has meaningful effects on reducing plane velocities in the reservoir. The maximum plane 


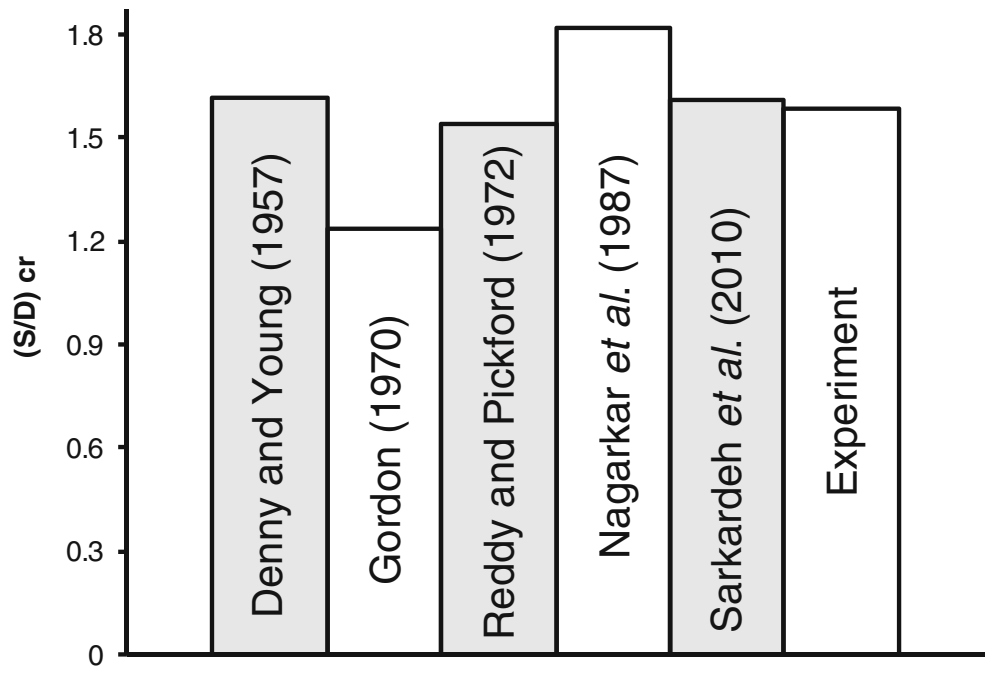

Figure 5. Comparison between empirical equations for predicting $S_{C}$ in horizontal intake.

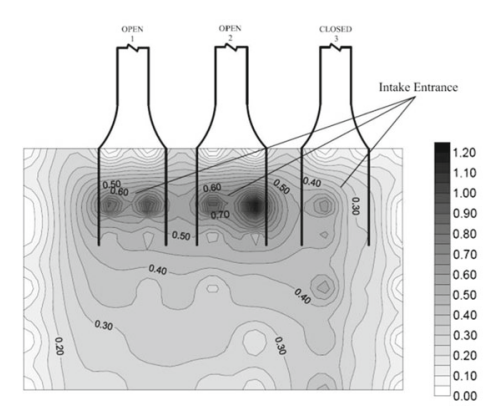

Measurement Level $=$ Intake Axis

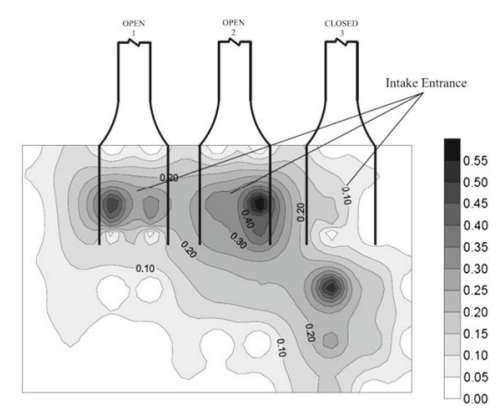

Measurement Level $=$ Near the Water Surface

Figure 6. Plane view of power intake by presenting velocity contour lines at $S / D$ equal to 1.6.

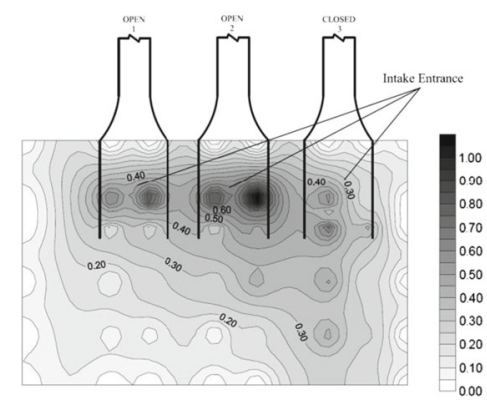

Measurement Level $=$ Intake Axis

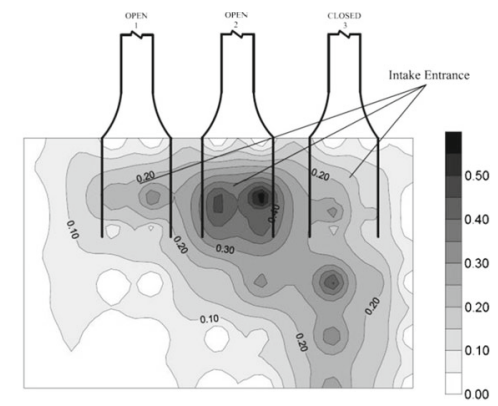

Measurement Level $=$ Near the Water Surface

Figure 7. Plane view of power intake by presenting velocity contour lines at $S / D$ equal to 2.4. 


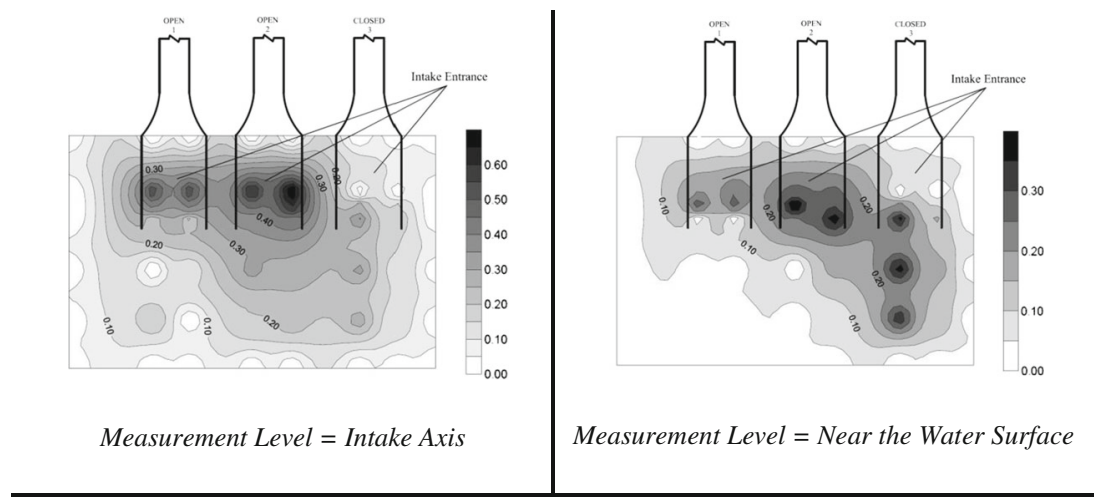

Figure 8. Plane view of power intake by presenting velocity contour lines at $S / D$ equal to 3.2.

velocity near the water surface decreased about $30 \%$, and the maximum plane velocity decreased at the intake axis about $40 \%$ by increasing relative submerged depth from 1.6 to 3.2.

Sediment transport to the power intake is a challenging engineering problem in water withdrawal from the reservoir which could damage tunnel lining and also turbines (Knauss 1987). In a real life scenario, the power intake always is at higher elevations of a dam and therefore the sediments could not reach the intake entrance easily. Formation of a free surface vortex at the water surface could be collaborated with a submerged vortex. Sarkardeh et al (2013) reported formation of a bottom conical flow which may convey sediment from the reservoir bottom to the intake. Therefore, it seems that the power intake must be far enough from the reservoir bottom to be safe from the sediment suction by a formed submerged vortex.

\section{Conclusions}

Formation of vortices at power intakes is an undesirable phenomenon, with several problems. Stronger vortices have more negative effects on the performance of the hydropower plant. The results of experiments on the hydraulic model of Karun III dam and hydropower plant is used to study the effect of vortex formation in the reservoir on the flow behaviour towards the intake. In the present experimental study, at the first series of the experiments, critical submerged depth was estimated and was compared with the available empirical equations. At the second part of the experiments, by measuring the plane velocities in the reservoir, the plane velocity contour lines were plotted at three different submerged depths. To determine the vortex class in each test, light colorful objects were released in the flow. Results of the experiments showed that the critical relative submerged depth was equal to 1.6. Therefore, Denny \& Young (1957) and Sarkardeh et al (2010) predicted critical submerged depth closer to the result of experiment. However, Gordon (1970) and Reddy \& Pickford (1972) underestimated and Nagarkar et al (1987) overestimated the $S_{c r}$. Moreover, velocity measurements in the reservoir showed that increasing the submerged depth has meaningful effect on reducing plane velocities in the reservoir. The maximum plane velocity close to the water surface, by increasing submerged depth from 1.6 to 3.2 , decreased about $30 \%$. Also, the maximum plane velocity decreased at the intake axis about $40 \%$ by increasing the submerged depth from 1.6 to 3.2 . 


\section{Acknowledgements}

The authors thank the Hydraulic Structures Division of the Water Research Institute, Tehran, Iran for their permission for using the model data.

\section{References}

Amiri S M, Zarrati A R, Roshan R and Sarkardeh H 2011 Surface vortex prevention at power intakes by horizontal plates. J. Water Manag. (ICE), 164(4): 193-200

Amphlett MB 1976 Air Entraining Vortices at Horizontal Intake. HRC Wallingford Rep., No.OD/7

Anwar H O and Amphlett M B 1980 Vortices at Vertically Inverted Intakes. J. Hydraul. Res., 18(2): 123 136

Anwar H O, Weller J A and Amphlett M B 1978 Similarity of Free Vortex at Horizontal Intake. J. Hydraul. Res., 2: 95-105

Berge J P 1966 A Study of Vortex Formation and Other Abnormal Flow in a Tank with and without a Free Surface. La Houille Blanche No 1

Camnasio E, Orsi E and Schleiss A J 2011 Experimental study of velocity fields in rectangular shallow reservoirs. J. Hydraul. Res., 49(3): 352-358

Carriveau R, Kopp G and Baddour R 2009 Stretching-sustained Intake Vortices. J. Hydraul. Res., 47(4): 486-491

Chang E 1977 Review of literature on drain vortices in cylindrical tanks. BHRA Rep. TN 1342

Chen Z, Ettema R and Lai Y 2004 Ice-tank and numerical study of frazil ingestion by submerged intakes. ASCE J. Hydraul. Eng., 130(2): 101-111

Constantinescu G S and Patel V C 1998 Numerical model for simulation of pump-intake flow and vortices. J. Hydraul. Eng., 124(2): 123-134

Constantinescu G S and Patel V C 2000 Role of turbulence model in prediction of pump-bay vortices. J. Hydraul. Eng., 126(5): 387-391

Daggett L L and Keulegan G H 1974 Similitude in free-surface vortex formation. ASCE J. Hydraul. Div., 100(11): 1565-1580

De Siervi F, Viguier H C, Greitzer E M and Tan C S 1982 Mechanisms of inlet-vortex formation. J. Fluid Mech., 124: 173-207

Denny D F and Young G H J 1957 The Prevention of Vortices and Swirl at Intakes. IAHR Cong Lissabon, paper $\mathrm{C} 1$

Gordon J L 1970 Vortices at Intakes. Water Power Apr. 137-138

Hite J E and Mih W 1994 Velocity of Air-Core Vortices at Hydraulic Intakes. J. Hydraul. Eng., 120(3): 284-297

Jain A K, Raju K G R and Garde R J 1978 Vortex Formation at Vertical Pipe Intake. J. Hydraul. Eng., 100(10): 1427-1445

Johnson PL 1972 Hydraulic Model Studies of the Forebey Reservoir Inlet-Outlet Structures for Mt. Elbert Pumped-storage Power Plant. USBR, Washington, DC, Rep. Rec-Erc-72-5

Knauss J 1987 Swirling Flow Problems at intakes, Balkema

Montazerin N, Rahimzadeh H and Hashemi Marghzar Sh 2001 Prediction of Critical Condition at a Horizontal Intake through Pressure Contours XXIX IAHR Cong. China

Nagarkar P K, Grampurohit K A, Ghodke C V, Jogdand E B and Kulkarni D B 1987 Submergence Criteria for Hydro-Electric Intakes. J. Water Energy Int., 44(3): 59-80

Odgaard J A 1986 Free-surface air core vortex. J. Hydraul. Eng., 112(7): 610-620

Padmanabhan M and Hecker G E 1984 Scale effects in pump sump models. J. Hydraul. Eng., 110(11): $1540-1556$

Rankine W J M 1858 Manual of applied mechanics. London, UK: C. Griffin \& Co.

Reddy Y R and Pickford J A 1972 Vortices at Intakes in Conventional Sumps. Waterpower 108-109 
Sarkardeh H 2009 Effect Of reservoir vortex on flow condition at power tunnels. M.Sc. Thesis. Amirkabir University of Technology (Tehran Polytechnic). Tehran. Iran

Sarkardeh H, Jabbari E, Zarrati A R and Tavakkol S 2013 Velocity field in a reservoir in the presence of an air-core vortex. J. Water Manag. (ICE), 164(4): 193-200

Sarkardeh H, Zarrati A R and Roshan R 2010 Effect of intake head wall and trash rack on vortices. J. Hydraul. Res., 48(1): 108-112

Sarkardeh H, Zarrati A R, Jabbari E and Roshan R 2012 Discussion of Prediction of Intake Vortex Risk by Nearest Neighbors Modeling. J. Hydraul. Eng. ASCE, 137(6): 701-705

Taghvaei S M, Roshan R, Safavi Kh and Sarkardeh H 2012 Anti-vortex structures at hydropower dams. Int. J. Phys. Sci., 7(28): 5069-5077

Travis Q and Mays L 2011 Prediction of Intake Vortex Risk by Nearest Neighbors Modeling. J. Hydraul. Eng., 137(6): 701-705

Yildirim N, Eyüpoğlu A and Taştan K 2012 Critical Submergence for Dual Rectangular Intakes. J. Energy Eng., 138: 237-245 